Research Article

\title{
Numerical Study on Failure Mechanisms of Shaft Wall Consisting of Steel Plate and Concrete under the Effects of Explosion
}

\author{
Yanjun Qi, ${ }^{1,2}$ Linming Dou, ${ }^{2}$ Zhaoxing Dong $\mathbb{D}^{1},{ }^{1}$ and Bo Meng ${ }^{1}$ \\ ${ }^{1}$ School of Mechanics and Civil Engineering, China University of Mining and Technology, Xuzhou 221116, China \\ ${ }^{2}$ State Key Laboratory of Coal Resources and Safe Mining, China University of Mining and Technology, Xuzhou 221116, China \\ Correspondence should be addressed to Zhaoxing Dong; dongzx1966@163.com
}

Received 17 March 2021; Revised 6 April 2021; Accepted 12 April 2021; Published 24 April 2021

Academic Editor: Rihong Cao

Copyright (c) 2021 Yanjun Qi et al. This is an open access article distributed under the Creative Commons Attribution License, which permits unrestricted use, distribution, and reproduction in any medium, provided the original work is properly cited.

\begin{abstract}
To enhance the antidynamic and static load resistance of reinforced concrete structures, the measure of covering steel plates on the inner surface of concrete structures arises, which has been rapidly developed and applied in civil engineering and other fields and has achieved a good performance. A new shaft wall structure consisting of steel plate reinforced concrete has been widely used in shaft of deep mining. In order to investigate the stability and obtain the optimum structure parameters of the new shaft structure, the numerical software of LS-DYNA was used to analyze the influences of different factors, including the explosive payload, steel plate thickness, concrete strength grade, and the included joint angle between two plates, on the stability of steel plate reinforced concrete structures. After the verification of the accuracy of numerical simulation results, 23 simulation schemes were proposed and numerically calculated. For all the tests, the principal tensile stress and particle vibration velocity were, respectively, chosen as the failure criteria to evaluate the impacts of those four factors. The results indicate that a quadratic function can be well used to describe the relationships between each factor and both the principal tensile stress and particle vibration velocity. Based on the results, the optimum structure parameters were finally determined, which are suggested as $250 \mathrm{~kg}, 15 \mathrm{~mm}, \mathrm{C} 85$, and $40^{\circ}$ for the explosive payload, steel plate thickness, concrete strength grade, and joint angle, respectively. The research results can provide a certain theoretical basis and design guidance for solving the problem of water leakage of single-layer shaft wall structures.
\end{abstract}

\section{Introduction}

With the depth increase of coal mine in China, great breakthrough has been made in the deep freezing technology. Meanwhile, the new shaft wall structure, which consists of the concrete body and steel joint plates, is bound to replace the past unreasonable single wall structure which is a superthick and simple structure. The key technology to ensure the integrity and water resistance is how to avoid the failure in concrete and along the interface between the concrete and steel plate under an applied explosive load $[1,2]$. The main methods used to study the issue include model test and numerical simulation. Because of the accuracy and reliability of the numerical simulation, with big difficulty and high cost of the model test, numerical simulation has been the most practical and efficient method.

Based on the study on the bend and failure modes of both the beam and plate structure under an applied explosive load, a simplified resistance model and an equivalent system of degree of freedom (DOF) of the beam and plate were proposed [3-6]. The reliability of the numerical simulation was proved by comparing the numerical simulation results using the finite element method (FEM) software and the real explosion tests of the dynamic response of concrete under an applied explosive load $[7,8]$. The dynamic response of the concrete wall under explosion effects was obtained [9], and similar studies have been conducted by other reports $[10,11]$. The deformation rules of concrete walls under an explosive load were gained from the numerical simulation 
using the software of ANSYS/LS-DYNA [12, 13], and the dynamic response characteristics and failure patterns of the reinforced concrete slab subjected to an applied explosive load were investigated using both the experimental tests and FEM simulations [14-16]. All those reports used numerical simulations as an important means to analyze the mechanical properties of concrete under explosion. In addition, the reliability and accuracy of numerical simulations have also been verified.

Many works, including both the theoretical calculation and numerical simulation, have been conducted to study the mechanical and stability characteristics of steel plate reinforced concrete (SPRC) structure under an applied explosive load. The break characteristics of SPRC structures under an explosive load were investigated by analyzing the changes of the deformation and stress theoretically $[17,18]$. The study results determined that the existence of steel plate decreases the crack in the concrete dramatically. By using a theoretical calculation model, a proper rockconcrete-steel plate example was built [19], and based on the example, the reinforcement mechanisms of steel plate and propagation mechanisms of waves in different media have been studied. A new calculation method of SPRC obtained from physical scaled model tests, which has been used in the engineering design, was proposed [20-22]. The numerical simulation that used ANSYS/LS-DYNA was performed to study the stability of tunnel lining structures under an applied explosive load, and the composite materials greatly improved the antiexplosion performances of the concrete [23]. Based on layered civil air defense works, a design scheme of layered civil air defense works used Split Hopkinson Pressure Bar (SHPB) and physical model tests were proposed [24-26]. In order to study the influence of explosive loads on the collapse of reinforced concrete slab, the software ANSYS/LS-DYNA was used to study the damage failure of the concrete and propose a new collapse calculation formula [27-29].

The focus of this study is to determine the break rules and optimum structural forms of SPRC sidewalls under an applied explosive load by using the FEM numerical simulations. The influence of different factors, including the explosive payload, thickness of steel plate, concrete strength, and joint angle of plate, was systematically studied. Based on the simulation results, the optimum design parameters of the sidewall were obtained.

\section{Basic Theory of Stress Wave Propagation}

The range of stress waves is a typical plastic zone, and the rock medium will be damaged and elastically deformed; thus, both continuous and residual deformation of the rock transfer disturbance should be considered. After the shock wave enters the middle zone of blasting, its properties and waveforms have changed greatly. The relationship between the maximum radial component and the maximum tangential component of the particle velocity on the wave front and the maximum radial pressure and the maximum tangential pressure on the wave front is as follows:

$$
\begin{gathered}
\sigma_{r \text { max }}=\rho_{0} C_{1} V_{r \text { max }}, \\
\sigma_{\theta \text { max }}=\rho_{0} C_{1} V_{\theta \text { max }},
\end{gathered}
$$

where $\rho_{0}$ is the rock density, $C_{1}$ is the P-wave velocity in the rock, $V_{r \max }$ and $V_{\theta \max }$ are the maximum radial component and the maximum tangential component of the particle velocity on the wave front, and $\sigma_{r \max }$ and $\sigma_{\theta \max }$ are the maximum radial pressure and the maximum tangential pressure on the wave front.

Displacement of the particles corresponding to the time of $t$ under applied positive pressures is as follows:

$$
d=\int_{0}^{x} V(t) \mathrm{d} t .
$$

The impulse density can be calculated as

$$
I_{p}=\rho_{0} C_{1} \int_{0}^{x} V(t) \mathrm{d} t=\rho_{0} C_{1} d .
$$

The energy flux density is

$$
\begin{gathered}
W_{p}=\rho_{0} C_{1} \int_{0}^{x} V(t) \mathrm{d} t, \\
W_{p}=\frac{1}{\rho_{0} C_{1}} \int_{0}^{x} \sigma^{2}(t) d_{t}=\rho_{0} C_{1} d .
\end{gathered}
$$

Total energy of waves can be obtained:

$$
W_{t}=W_{p} S .
$$

Because there is a cohesive force at the interface between the concrete and rock and there is no sliding at the interface, thus the displacement, particle velocity, and stress at the interface are continuous. The reflection stress and transmission stress of the normal incidence can be calculated.

$$
\left\{\begin{array}{l}
\sigma_{r}=\sigma_{i} \frac{\rho_{1} C_{2}-\rho_{0} C_{1}}{\rho_{1} C_{2}+\rho_{0} C_{1}}, \\
\sigma_{t}=\frac{2 \sigma_{i} \rho_{1} C_{2}}{\rho_{1} C_{2}+\rho_{0} C_{1}},
\end{array}\right.
$$

where $\rho_{2}$ is the density of concrete.

\section{Engineering Situation}

3.1. Geological Conditions. An auxiliary shaft of a coal mine, whose design production capacity is $12 \mathrm{MT} / \mathrm{a}$, was analyzed as the engineering background in this paper. The geological lithology of the mine, which has large inclined bedding and cross bedding, is mainly brown-red coarse-medium-grained sandstone, followed by fine-grained sandstone. The rock is argillaceous and cementation, mainly composed of feldspar and quartz, with subangular particles and medium sorting, presenting unconformity contact with the underlying stability group (J2A). The softening coefficient of all kinds of rocks in this area is less than 0.75 , which is easy to be softened, and the core can be crushed by hand. The strength of the rock is equivalent to the weathered rock, and the 
weathering resistance of the rock is very weak. Under normal circumstances, the core will be broken after exposure for 2-3 days.

3.2. Structure and Size of Shaft Wall. The net diameter of the auxiliary shaft is $10.0 \mathrm{~m}$, the depth of the shaft is $755 \mathrm{~m}$, and the whole shaft is constructed by using the freezing method. The single-layer shaft wall of the frozen bedrock section is sunk by using the drilling and blasting method, which saves investment and speeds up the sinking speed, and overcomes the shortcomings of thick, high cost, and slow construction of the double-layer composite borehole wall.

The study object in the numerical simulation model is the depth range from $-320 \mathrm{~m}$ to $-580 \mathrm{~m}$ of the shaft wall. To improve the sealing performance of jointing parts of the borehole wall, the steel plate was applied as the joint to prevent seepage, which constitutes SPRC structures with concrete of the shaft wall. The SPRC structure is shown in Figure 1.

\section{Model Building and Parameters Determination of the Numerical Simulation}

4.1. Model Building. The shape, size, and boundary of the model are all displayed in Figure 2. According to the site condition, the shaft radius was set at $5 \mathrm{~m}$ and the concrete wall thickness was set at $0.95 \mathrm{~m}$. In order to reduce the influence of boundary effects and ensure the accuracy of the simulation results, the outer diameter and height of the model were set at $30 \mathrm{~m}$ and $25 \mathrm{~m}$, respectively. In order to reduce the computational time, the $1 / 4$ cylinder model of the overall model was established, and the radial boundary of the $1 / 4$ model was set as the symmetric boundary condition. Since the upper, lower, and outer parts of the selected part could be regarded as semi-infinite spaces, those boundaries were set as nonreflective boundaries. In addition, only the total charge mass was taken into account in this paper, and the influence of the blast hole layout was neglected. Therefore, concentrated charge and primary detonation were used in the model. In order to study the secondary influence of explosion on the constructed steel sheet concrete composite structures, two (upper and lower) SPRC structures were established when building the model.

The model was built and meshed using the software of ANSYS and the material parameters are defined in LSDYNA. The established numerical simulation model of the vertical shaft wall is shown in Figure 2.

4.2. Determination of the Material Parameters. Dynamic analysis software LS-DYNA was used for numerical simulation analysis in this study. The built model includes the explosive unit, concrete unit, surrounding rock medium unit, and steel unit, all of which are solid elements under dynamic loads, and the SOLID164 solid unit was selected.

In LS-DYNA, the material of MAT_HIGH_EXPLOSIVE_BURN was used to simulate high explosive materials and the state equation of EOS_JWL was applied to control the explosion process. In the initialization stage, the ignition

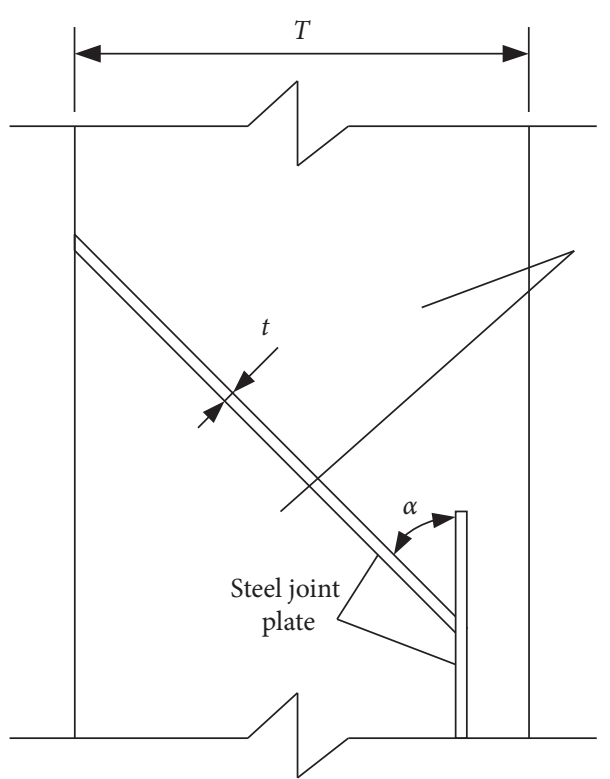

FIgURE 1: Layout Schematic of the SPRC structure in shaft wall.

time $t_{1}$ at the centroid (i.e., the position of the integration point) of each unit is calculated, which is equal to the distance $L$ between the centroid of the unit and the detonation point divided by the detonation velocity $D$ of the explosive. At time $t$, the combustion reaction rate $F$ of the unit is as follows:

$$
\begin{aligned}
F & =\max \left(F_{1}, F_{2}\right), \\
F_{1} & = \begin{cases}\frac{2\left(t-t_{1}\right) D}{3\left(V_{e} / A_{e \max }\right)}, & t>t_{1}, \\
0, & t \leq t_{1},\end{cases} \\
F & =\frac{1-V}{1-V_{c j},}
\end{aligned}
$$

where $V e$ is the unit volume, $A_{e \max }$ is the maximum unit area, $V$ is the relative unit volume, and $V_{c j}$ is the Chapman Jouguet pressure.

The form of the EOS_JWL state equation is as follows:

$$
P=A\left(1-\frac{\omega}{R_{1} V}\right) e^{-R_{1} V}+B\left(1-\frac{\omega}{R_{2} V}\right) e^{-R_{2} V}+\frac{\omega E_{0}}{V},
$$

where $A, B, R_{1}, R_{2}$, and $\omega$ are state coefficients characterizing explosive properties and $E_{0}$ is the initial internal energy density.

According to the water-gel explosive used in the field, the parameters of the simulated explosive and state equation of JWL are shown in Table 1 , where $\rho$ is the density, $D$ is the detonation velocity, $E_{0}$ is the initial internal energy of detonation, and $P_{c j}$ is the detonation pressure. Other parameters are constantly used in the state equation.

The elastoplastic material of MAT_PLASTIC_KINEMATIC in LS-DYNA was applied to simulate the rock and concrete in this paper. The material model is a typical 


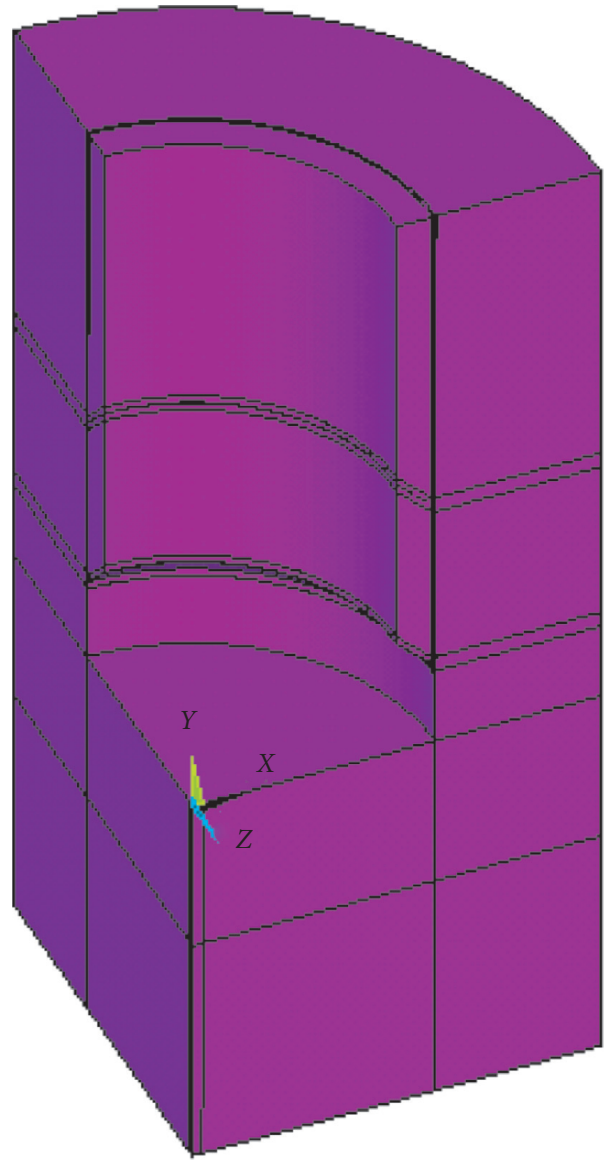

(a)

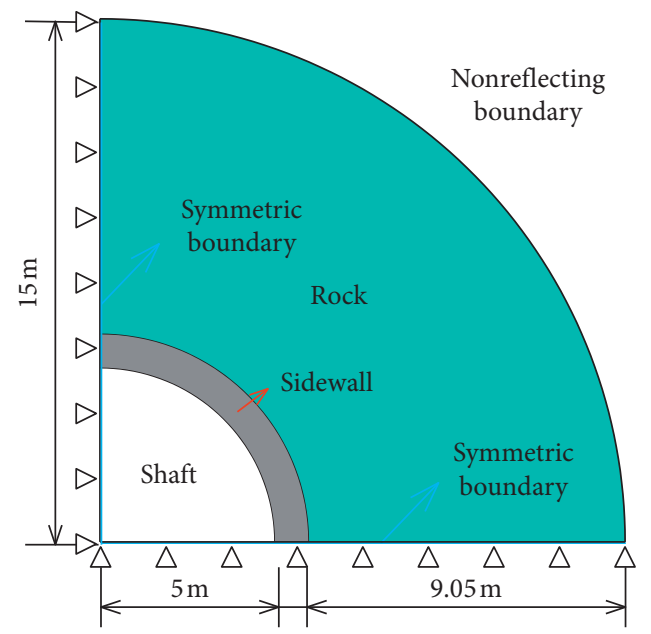

(c)

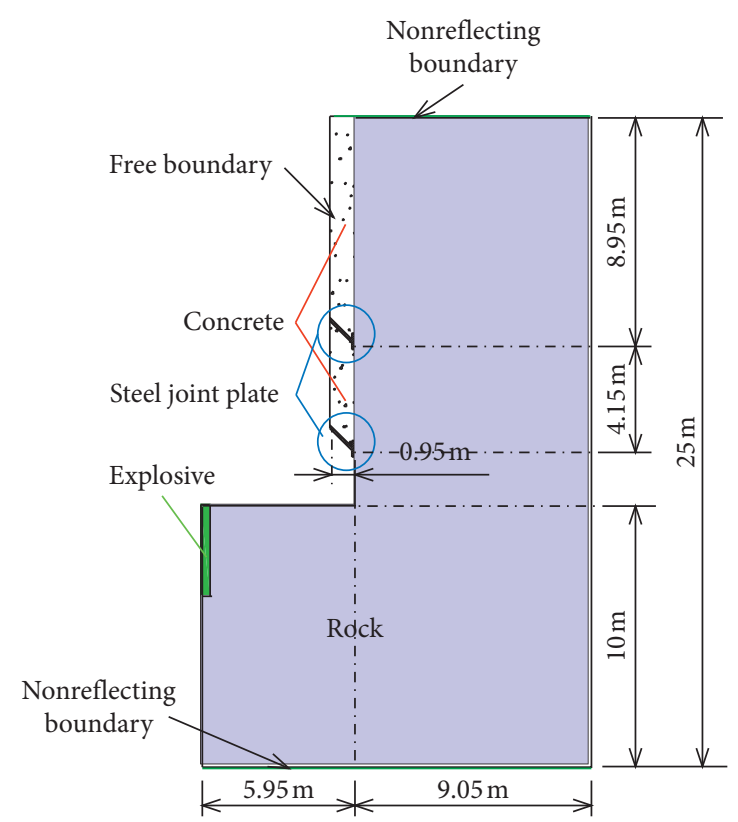

(b)

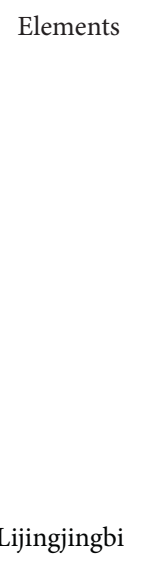

(d)

Figure 2: Numerical simulation model of the vertical shaft wall. (a) Schematic diagram of the model. (b) Front view of the model. (c) Top view of the model. (d) Meshing of the model.

Table 1: Parameters used in the explosive materials and state equation.

\begin{tabular}{lcccccccc}
\hline$\rho\left(\mathrm{g} / \mathrm{cm}^{3}\right)$ & $D(\mathrm{~m} / \mathrm{s})$ & $P_{c j}(\mathrm{GPa})$ & $A /(\mathrm{GPa})$ & $B /(\mathrm{GPa})$ & $R_{1}$ & $R_{2}$ & $\omega$ & $E_{0} / \mathrm{J} / \mathrm{m}^{3}$ \\
\hline 1.02 & 4000 & 5.3 & 374 & 7.33 & 4.15 & 0.95 & 0.30 & $7 * 10^{9}$ \\
\hline
\end{tabular}


kind of isotropic and follow-up hardening mixture, which is related to the strain rate and takes the failure into account. The same material model was applied to simulate the rock and concrete, with the parameters shown in Table 2.

Generally, under the action of stress waves, the steel plate is considered to produce elastic deformation only, without plastic deformation or failure; thus, the elastic *MAT_JOHNSON_COOK material mode was selected. The parameters of the steel and state equation of GRUNEISEN are shown in Table 3.

\subsection{Determination of the Simulation Experimental Scheme.} In order to maximize economic benefits, new mines are often required to be built and put into production as soon as possible. Therefore, in the process of shaft excavation, the construction party often increases the explosive charge quantity in pursuit of progress. The larger amount of primary explosives will induce serious influences on the wellbore structures. Therefore, in order to clarify the specific impacts of the change of the explosive quantity on the steel plate concrete composite structures in shaft lining, this paper will study the dynamic response of the steel plate concrete composite structure under different explosive quantities based on the actual explosive quantity, from which, whether the current explosive quantity is reasonable is judged and the appropriate explosive quantity is obtained.

The increase of the steel plate thickness has little effect on the propagation of stress waves, while the tensile stress at the steel plate concrete interface will decrease significantly. The particle vibration velocity will only change the component size in each direction and has little effect on the actual particle vibration velocity. Therefore, this paper mainly studies the influence of the change of the steel plate thickness on the structural stress and determines the reasonable steel plate thickness.

The wave impedance of two adjacent media determines both the direction and value of the reflection and transmission of stress waves, and the change of the concrete strength grade will not affect the propagation of stress waves. When the stress wave causes the same stress in the steel plate and concrete, damage may occur when the strength grade of the concrete is too low. However, if the strength of the concrete is too high, it will not only increase the particle velocity but also make the strength surplus too large and cause waste. Therefore, it is necessary to study this factor and determine the reasonable strength grade of the concrete.

Considering the convenience of assembly and lifting, the included angle between the vertical and inclined steel plates is designed to be $45^{\circ}$ in engineering fields. The changing included angles will vary the propagation path of the stress wave to some extent, resulting in differences between the reflection and transmission of stress waves and differences between the stress value and particle vibration velocity responses. Therefore, it is necessary to study the influences of the included angle between the steel plate and concrete and finally determine the appropriate angle.

Combined with the engineering practice, the influences of four factors including the explosive payload, thickness of
TABLE 2: Parameters of related rock and concrete.

\begin{tabular}{lcccc}
\hline Item & $\rho /\left(\mathrm{g} / \mathrm{cm}^{3}\right)$ & $E /(\mathrm{GPa})$ & $\mu$ & Yield stress $(\mathrm{MPa})$ \\
\hline Rock & 2.12 & 10 & 0.22 & 35 \\
Concrete & 2.50 & 35 & 0.19 & - \\
\hline
\end{tabular}

TABle 3: Parameters of the related steel plate.

\begin{tabular}{cccccccc}
\hline Item & $\rho /\left(\mathrm{g} / \mathrm{cm}^{3}\right)$ & $E /(\mathrm{GPa})$ & $\mu$ & $C$ & $S_{1}$ & $S_{2}$ & $V_{0}$ \\
\hline Steel & 7.8 & 210 & 0.27 & 0.45 & 1.49 & 0.0 & 1.0 \\
\hline
\end{tabular}

steel plate, concrete strength, and included angle between steel plates on the failure and security of SPRC structures were studied in this paper. The initial scheme of this shaft is as follows: quantity of the primary explosive is $215 \mathrm{~kg}$, thickness of steel plate is $8 \mathrm{~mm}$, strength grade of concrete is C65, and the included angle between the vertical and inclined steel plates is $45^{\circ}$, with the scheme number of " 215 8-65-45," based on which, 24 schemes were designed, as shown in Table 4.

4.4. Verification of the Numerical Simulation Results. In order to verify the accuracy of the numerical simulation results, the peak pressure values at different positions of the cylindrical charge with an explosive quantity of $215 \mathrm{~kg}$ were calculated and then compared with the numerical simulation results. According to the observation data of the impact pressure in rock with the distance, the relationship between the shock pressure and distance follows an attenuation law [30]:

$$
\sigma_{\max }=\frac{P_{r}}{\bar{r}^{\alpha}}
$$

where $\alpha=2_{-}^{+}(\mu / 1-\mu)$; this expression is positive in the shock wave propagation region and negative in the stress wave propagation region. $P_{r}$ is the pressure at the interface between the rock and explosive, $\bar{r}$ is the relative distance, $\bar{r}=R / R_{0}, R_{0}$ is the radius of the explosive, $R$ is the distance from the measure point to the explosive, and $\mu$ is Poisson's ratio.

The charge mode is a coupled cylindrical charge, according to the explosion force on the interface between the shock waves and stress waves, that is, the pressure at the interface between the rock and explosive, shown as the empirical formula [31]:

$$
P_{r}=\frac{2 \rho_{m} C_{p}}{\rho_{m} C_{p}+\rho_{e} D_{e}} * P_{e}
$$

where $\rho_{e}$ and $\rho_{m}$ are the density of the explosive and rock, respectively, $C_{p}$ is the longitudinal wave velocity in the rock, $D_{e}$ is the detonation velocity of the explosive, $\rho_{m} C_{p}$ and $\rho_{e} D_{e}$ are defined as the wave impedance of the rock and explosive, and $P_{e}$ is the detonation pressure of the explosive.

The explosion wave pressure at the interface of the blast hole at different positions calculated by equation (2) and obtained from the numerical simulations is tabulated in Table 5. The maximum error between the theoretical and 
TABLE 4: Numerical simulation schemes.

\begin{tabular}{lccccc}
\hline Item & \multicolumn{5}{c}{ Scheme } \\
\hline EP & $100-8-65-45$ & $150-8-65-45$ & $200-8-65-45$ & $215-8-65-45$ & $250-8-65-45$ \\
TSP & $215-6-65-45$ & $215-10-65-45$ & $215-12-65-45$ & $215-15-65-45$ & $215-20-65-45$ \\
CS & $215-8-C 25-45$ & $215-8-35-45$ & $215-8-45-45$ & $215-8-55-45$ & $215-8-75-45$ \\
JA & $215-8-65-30$ & $215-8-65-40$ & $215-8-65-45$ & $215-8-65-50$ & $215-8-65-60$ \\
\hline
\end{tabular}

TABle 5: Comparison of the theoretical calculation and numerical simulation results.

\begin{tabular}{lccc}
\hline $\begin{array}{l}\text { Position } \\
(\mathrm{m})\end{array}$ & $\begin{array}{c}\text { Theoretical } \\
\text { result }\end{array}$ & $\begin{array}{c}\text { Simulation } \\
\text { result }\end{array}$ & $\begin{array}{c}\text { Relative } \\
\text { error } \\
(\%)\end{array}$ \\
\hline 0 & 720 & 610 & 15 \\
0.5 & 207 & 212 & 2 \\
1.0 & 62.9 & 58.4 & 7 \\
3.0 & 9.5 & 9.2 & 3 \\
5.0 & 4.0 & 3.95 & 1 \\
\hline
\end{tabular}

numerical results is $15 \%$, and the calculated and numerical results show good consistency. Therefore, the simulation results can be considered accurate and reliable.

4.5. Failure Criteria. Due to the fact that the dynamic tensile strength of the rock and concrete materials is far less than its dynamic compressive strength, the material in the SPRC structure is prone to brittle failure when subjected to a tensile stress. Thus, the first strength theory (the maximum tensile stress theory) is taken as one of the criteria to judge whether the concrete is damaged. In blasting engineering, the maximum vibration velocity $\left(V_{\max }\right)$ of the structures should be less than some constants at a specific principal vibration frequency (PVF), as listed in Tables 6 and 7.

\section{Analysis of the Numerical Simulation Results}

As shown in Section 3.1, two steel joint layers were built in the simulation models, denoting the first layer and second layer from the bottom to top. Due to the numerous experimental groups, in order to reduce the workload, it is necessary to determine positions with the maximum stress and vibration velocity for analysis. In this study, scheme 215$8-65-45$ is taken as an example, by comparing the stress and vibration velocity in three different points (Figure 3 ) of the two layers to determine which one possesses the larger stress and vibration velocity.

When the explosive explodes, it first produces a shock wave with a very strong peak pressure, then attenuates to a stress wave, and finally becomes an elastic wave until it disappears. The stress wave propagation law of the stress waves in the infinite rock mass is relatively clear, which radiates from the blasting center to the surrounding. However, when the stress wave propagates in an irregular structure, it will be affected by the shape and nature of the medium, and it is difficult to accurately describe its real propagation process. Figure 4 presents a typical spread process of stress waves in the steel plate and concrete
TABLE 6: Vibration velocity requirement for a roadway.

\begin{tabular}{lccc}
\hline $\operatorname{PVF}(\mathrm{Hz})$ & $f \leq 10 \mathrm{~Hz}$ & $10 \mathrm{~Hz} \leq f \leq 50 \mathrm{~Hz}$ & $f>50 \mathrm{~Hz}$ \\
\hline$V_{\max }(\mathrm{cm} / \mathrm{s})$ & $15 \sim 18$ & $18 \sim 25$ & $20 \sim 30$ \\
\hline
\end{tabular}

TABLE 7: Vibration velocity requirement for the newly poured concrete.

\begin{tabular}{lllllllllll}
\hline $\begin{array}{l}\text { PVF } \\
(\mathrm{Hz})\end{array}$ & \multicolumn{4}{c}{$f \leq 10 \mathrm{~Hz}$} & $10 \mathrm{~Hz} \leq f \leq 50 \mathrm{~Hz}$ & \multicolumn{3}{c}{$f>50 \mathrm{~Hz}$} \\
\hline $\begin{array}{l}\text { Age } \\
\text { (day) }\end{array}$ & $<3$ & $3 \sim 7$ & $7 \sim 28$ & $<3$ & $3 \sim 7$ & $7 \sim 28$ & $<3$ & $3 \sim 7$ & $7 \sim 28$ \\
$\begin{array}{l}V_{\max } \\
(\mathrm{cm} / \mathrm{s})\end{array}$ & $1 \sim 2$ & $3 \sim 4$ & $7 \sim 8$ & $2 \sim 2.5$ & $4 \sim 5$ & $8 \sim 10$ & $2.5 \sim 3$ & $5 \sim 7$ & $10 \sim 12$ \\
\hline
\end{tabular}

structures. The stress wave reaches the steel plate concrete composite structure at about 2000 us, and the peak value of stress waves increases significantly at the composite structure, which is due to the fact that the wave impedance of the concrete is less than that of the steel plate. With the change of time, the stress wave continues to propagate upwards the second layer of the composite structure, but the peak value of the stress wave becomes smaller. Finally, it decays to the elastic wave until it disappears.

Then, the stress and vibration velocity values of 3 measure points (edge of the inclined steel plate, central section of the inclined plate, and the central section of the vertical plate) were, respectively, selected from the board and compared to finally determine the most dangerous point for research.

The tensile stress curves of those three points in the two steel platelayers are shown in Figure 5. The maximum principal tensile stress of the first steel plate appears at the central position of the inclined plate (number as point $\mathrm{B}$ ). From the stress history curve, it can be seen that the time when the stress value response begins to appear is the same as the time when the stress wave arrives, and the form of the main tensile stress curves and stress wave curves at the same position is basically the same. In Figure 5(a), the stress at point $B$ and the central position of the vertical plate (point $C$ ) are nearly equivalent. The reason can be explained as follows: the attenuation of the peak stress wave at point $C$ is smaller, and the induced principal tensile stress is larger than that at point B. Although the stress wave has been attenuated when propagating to the center of the steel plate, the stress waves propagated through other paths also reach this position. The stress superimposition effect results in the principal tensile stress at point B slightly larger than that of point C.

Comparing Figures 5(a) and 5(b), it is obvious that the time when the stress appears in the upper steel plate is 1000 us later than that of the lower steel plate, which follows the wave propagation rule. The maximum tensile stress at the 


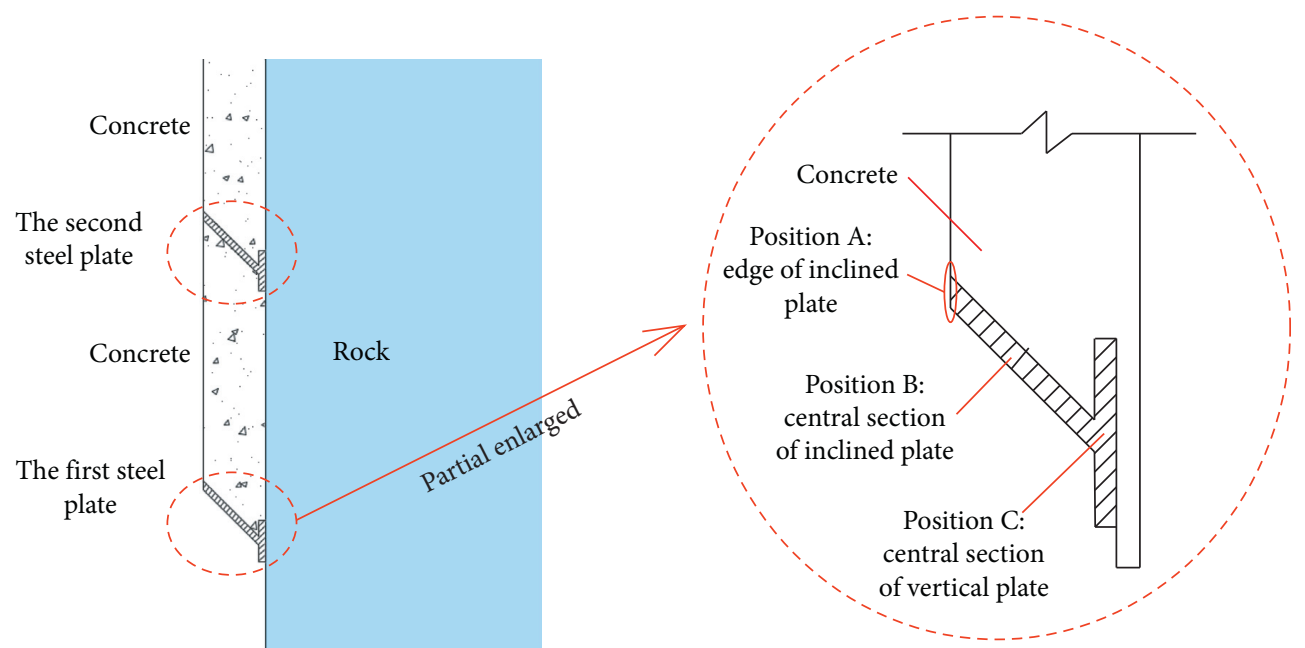

Figure 3: Partial enlargement of the joint plate.

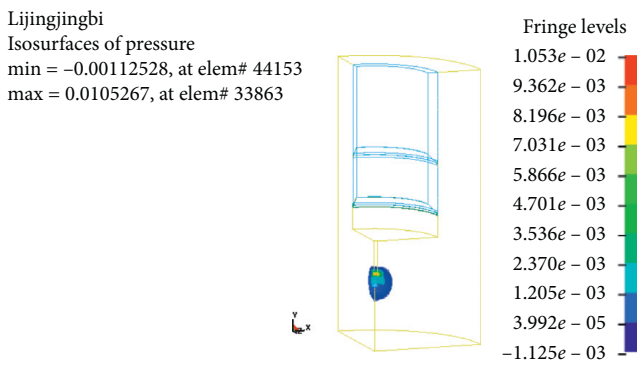

(a)
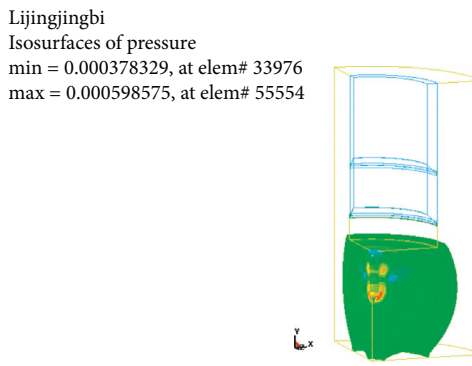

(c)

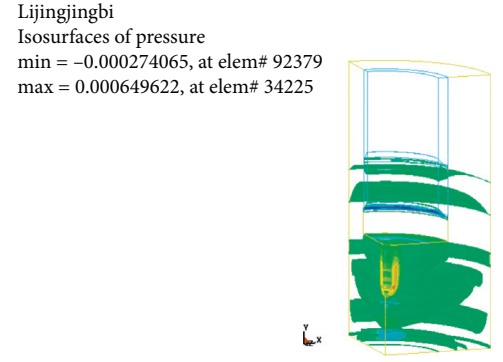

(e)

$5.986 e-04$

$5.009 e-04$

$4.032 e-04$

$3.055 e-04-$

$2.078 e-04$

$1.101 e-04$

$1.243 e-05$

$-8.526 e-05$

$-1.829 e-04$

$-2.806 e-04$

$-3.783 e-04$

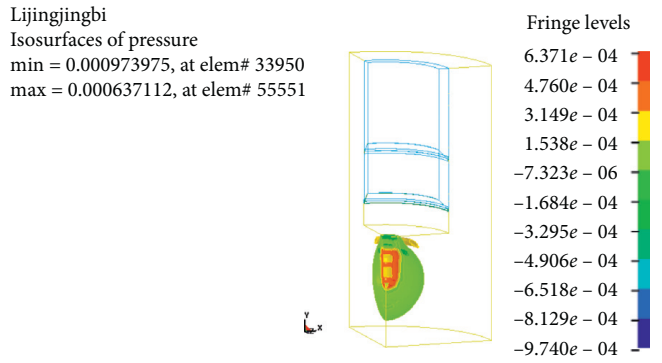

(b)

Lijingjingbi Isosurfaces of pressure $\min =0.000246725$, at elem\# 44754 $\max =0.000589856$, at elem\# 34466

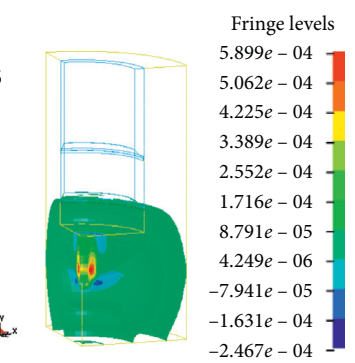

(d)

Lijingjingbi Isosurfaces of pressure $\min =-0.000148589$, at elem\# 92389 $\max =0.000584054$, at elem\# 34235

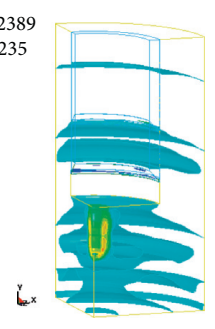

Fringe levels $5.841 e-04$ $5.108 e-04$ $4.375 e-04-$ $3.643 e-04-$ $2.910 e-04-$ $2.177 e-04-$ $1.445 e-04-$ $7.120 e-05-$ $-2.060 e-06-$ $-7.532 e-05-$ $-1.486 e-04$

(f)

Figure 4: Spread process of stress waves. (a) $t=300 \mathrm{us,} \mathrm{(b)} t=1100 \mathrm{us,} \mathrm{(c)} t=1700 \mathrm{us,}$, (d) $t=2000 \mathrm{us,} \mathrm{(e)} t=3000 \mathrm{us,}$ and (f) $t=5700 \mathrm{us}$. 


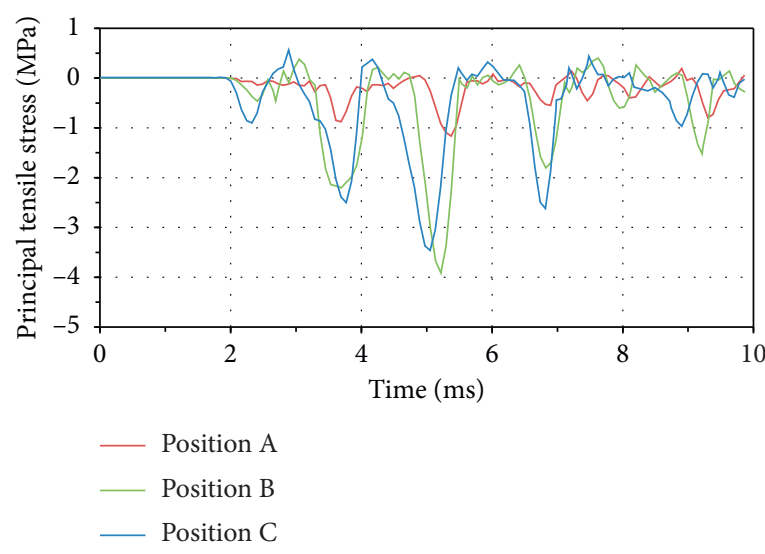

(a)

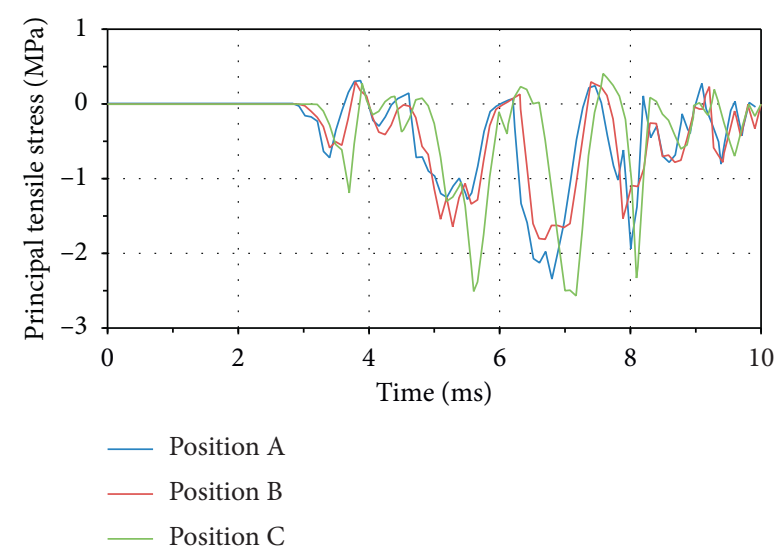

(b)

Figure 5: Principal tensile stress at different positions of the lower and upper steel plates. (a) Principal tensile stress curves at different positions of the lower plate. (b) Principal tensile stress curves at different positions of the upper plate.

upper steel plate is slightly smaller than that at the lower steel plate because the stress wave decays with the increase of the propagation distance and through different media, while the difference is not significant. In addition, for the upper steel plate, the maximum stress happens at point $C$, because of the superposition influence on the stress wave propagation caused by the irregularity of the whole wellbore structure, leading to different dynamic responses of those two steel joint plates. From the analysis above, point $\mathrm{B}$ at the lower (the central section of the inclined plate) is chosen as the study object to investigate the influences of different factors.

\subsection{Influence of the Explosive Payload}

5.1.1. Influence on the Principal Tensile Stress. With various explosive payloads, the principal tensile stress nephogram at the interface of the steel and concrete is shown in Figure 6(a). The principal tensile stress nephogram of the composite structure is basically the same at the same time with various primary explosive quantities. The stress response of the composite structure begins to appear at $2300 \mathrm{us,} \mathrm{and} \mathrm{the}$ stress value of the composite structure reaches the maximum at 5200 us.

The time history curves of the principal stress at point B with different explosive payloads are shown in Figure 6(b). The shape of the principal tensile stress curves and the time when the maximum stress appears are approximately the same with different explosive payloads, indicating that different explosive payloads have little effect on both the propagation speed and reflection law of the stress waves. For the amount of explosives of 100, 150, 200, 215, 250, and $300 \mathrm{~kg}$, the corresponding maximum tensile stress values are $2.7,3.2,3.7,4.0,4.1$, and $4.4 \mathrm{MPa}$, respectively. With the increase in the explosive payload, the maximum tensile stress increases significantly but the growth rate decreases gradually. Therefore, increasing the explosive payload has a great impact on the stability of the SPRC structures. It is suggested that the short footage tunneling and small explosive payload should be used in the construction process to protect the SPRC structures from damage.
The fitting curve of the relationship between the maximum tensile stress at the center of the steel plate and the explosive payload is shown in Figure 6(c). The growth speed of the maximum tensile stress first increases quickly and then slows down. Particularly, the value of the maximum tensile stress with the explosive payload of $215 \mathrm{~kg}$ and $250 \mathrm{~kg}$ is close. In order to make the blasting effect better, the explosive payload can also be appropriately increased to $250 \mathrm{~kg}$.

The dynamic strength of the concrete materials is significantly different with different strain rates. When the strain rate reaches $10^{2} / \mathrm{s}$, the dynamic tensile strength of the concrete materials could reach about 10 times larger than the static tensile strength [32]. With a continuous increase of the strain rate, the dynamic tensile strength of the concrete will increase greatly. The strain rate of the concrete can reach $10 \%$ s when subjected to stress waves, and the induced dynamic strength of the concrete will be very large. In this study, a concentrated charge with a radius of $0.13 \mathrm{~m}$ was used, and the scope of the stress wave was 120 150 times larger than the charging radius [33]. Obviously, the concrete in the model is in the scope of stress waves. However, the current study on the tensile strength of the concrete was under static conditions with standard maintenance and low strain rates. Few reports focus on the dynamic tensile strength of the concrete with short setting time and high strain rates; thus, it is not accurate to determine whether the structure is damaged only from the aspect of the dynamic tensile strength.

5.1.2. Influence on the Vibration Velocity. Because the maximum value of the first principal stress is greater than the absolute value of the third principal stress under the same factor, the maximum particle velocity in the positive direction should be greater than the maximum particle velocity in the negative direction. Thus, the maximum vibration velocity of the structure particle was selected as the study object in this section, and the positive vibration velocity of the particle at point B was analyzed. The time 


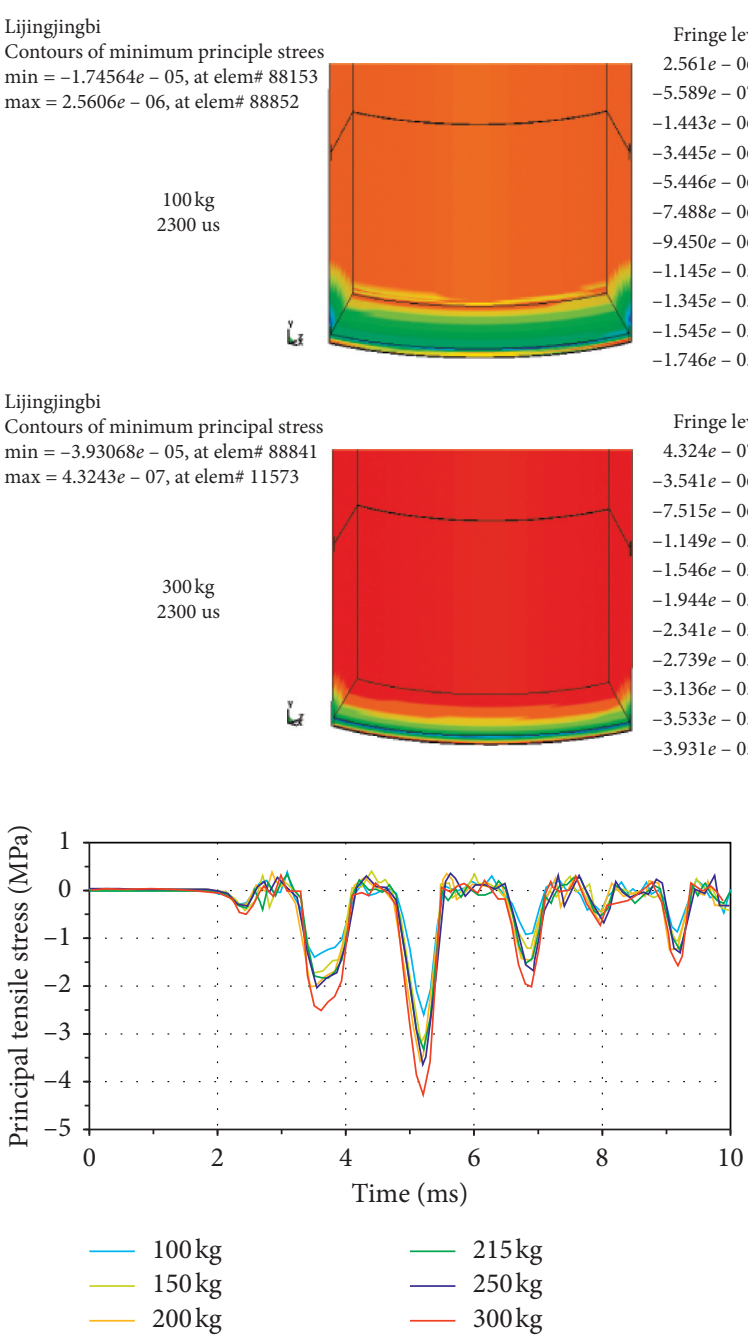

(b)

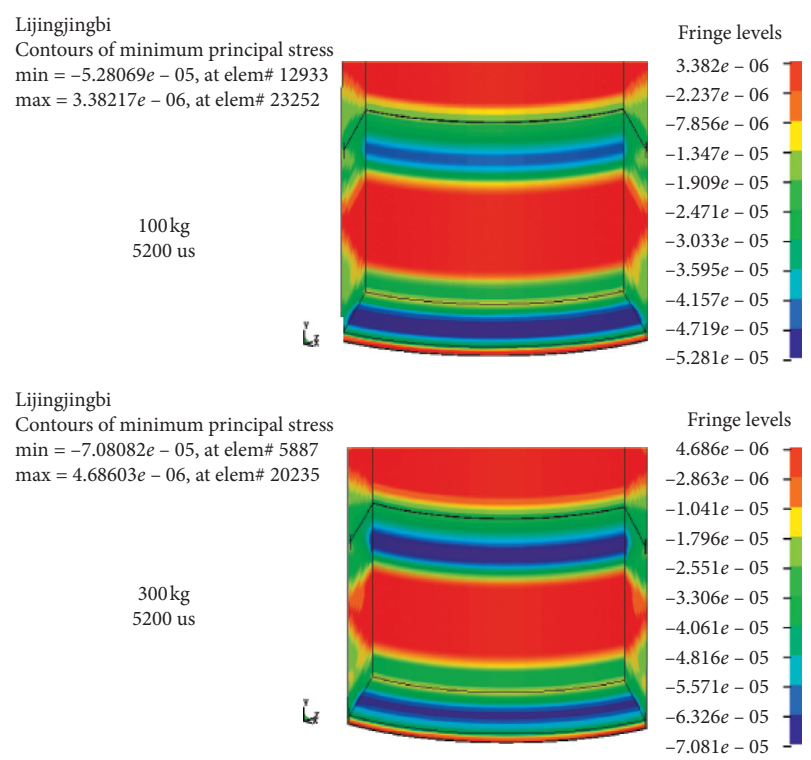

(a)

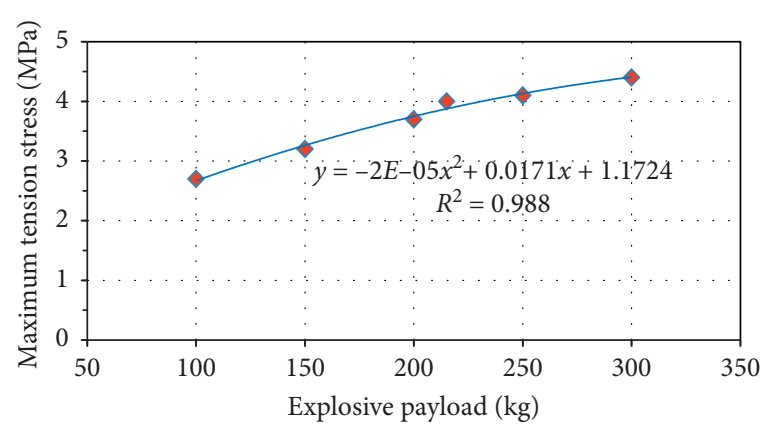

(c)

FIgURE 6: The relationships between principal tensile stress and explosive payloads. (a) Nephogram of the principal tensile stress at the center of the steel plate. (b) Principal tensile stress history curves with different explosive payloads. (c) Maximum tension stress with different explosive payloads in the steel center.

history curves of the particle vibration velocity at point $\mathrm{B}$ with different explosive payloads are shown in Figure 7(a).

From Figure $7(\mathrm{a})$, the vibration velocity increases with the increase in the explosive payload. Due to the fact that there is little influence of explosive payloads on the stress wave propagation, the shape of the vibration velocity curves and the corresponding time when the extreme values appear are generally consistent. The maximum particle vibration velocity at point $\mathrm{B}$ with six different groups of explosive payloads is $1.8 \mathrm{~cm} / \mathrm{s}, 2.4 \mathrm{~cm} / \mathrm{s}, 2.7 \mathrm{~cm} / \mathrm{s}, 3.0 \mathrm{~cm} / \mathrm{s}, 3.1 \mathrm{~cm} / \mathrm{s}$, and $3.4 \mathrm{~cm} / \mathrm{s}$, respectively, and the fitting curves of the relationships between the maximum particle vibration velocity and the detonating charge are plotted in Figure $7(\mathrm{~b})$.

By means of the postprocessing software of LS-Prepost, the main vibration frequency was obtained after the transformation of the particle vibration curves by FFT (fast Fourier transform), and the calculated main frequency of the structure is $633 \mathrm{~Hz}$. In the engineering field, the concrete setting time is about $3 \sim 7$ days when the blasting construction is applied. Table 7 in Section 3.5 shows that the safety vibration velocity of the concrete in this study is $5 \sim 7 \mathrm{~cm} / \mathrm{s}$. According to the numerical simulation results, when the explosive payload is $250 \mathrm{~kg}$, the maximum particle vibration velocity is $3.1 \mathrm{~cm} / \mathrm{s}$, which is still smaller than the safety vibration velocity of the particles. Hence, a visible increase of the explosive payload would not result in particle vibration velocities of the SPRC structures exceeding the security scope. Thus, taking the economy and reducing the stress value and particle vibration velocity into account, it is suggested that the explosive dosage should be increased to $250 \mathrm{~kg}$.

\subsection{Influence of the Thickness of Steel Plates}

5.2.1. Influence on the Principal Tensile Stress. The nephogram and the time history curves of the principal tensile stress at point $\mathrm{B}$ as well as the fitting curves of the relations between the third principal stress and thickness of the steel 


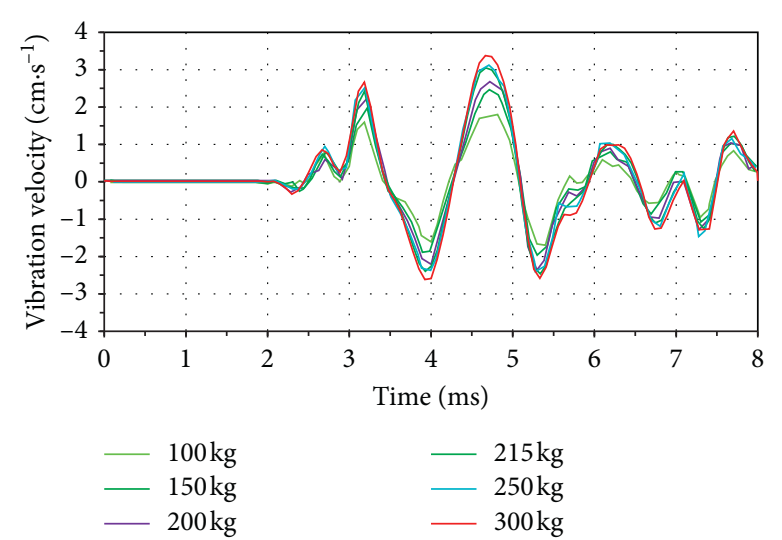

(a)

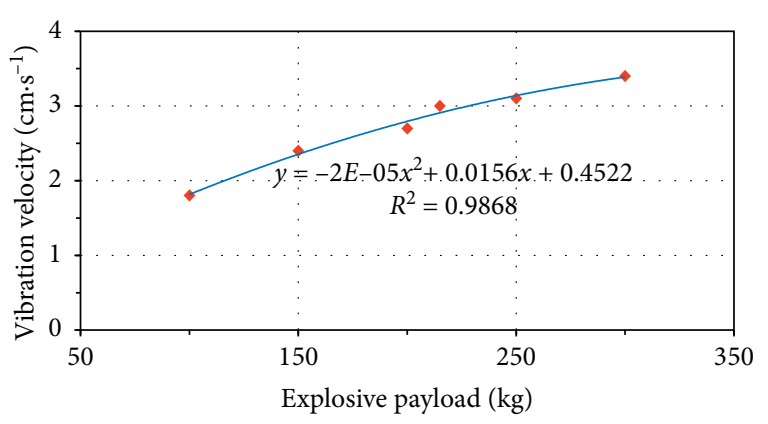

(b)

FIGURE 7: Vibration velocity of steel central position with different explosive payloads. (a) Velocity history curves of particle under different explosive payloads. (b) Positive velocity fitting curve under different explosive payloads.

plates are shown in Figure 8. With various thicknesses of steel plates, the principal tensile stress nephogram of the composite structure is basically the same at the same (Figure 8(a)). From Figure 8(b), the shape of the main tension curves is basically unchanged with various steel plate thickness, and the time when the peak tensile stress appears is generally the same, indicating that the thickness of steel plates has little influence on the propagation path of stress waves in the SPRC structures. The maximum tensile stress at the central position of the vertical plate with various thicknesses is $4.2,4.0,3.7,3.6,3.4$, and 3.1 $\mathrm{MPa}$, respectively. The maximum tensile stress decreases significantly with increasing plate thickness. Therefore, it is suggested that the thickness of the steel plates should be increased in the structural design to protect the composite structures of both steel plate and concrete from damage.

From the fitted curve in Figure 8(c), the increasing thickness of the steel plate leads to a reduction of the tensile stress of both the steel plate and concrete, and the reduction rate gradually diminishes. In practical engineering, the principal stress of the steel plate with a thickness of $8 \mathrm{~mm}$ is 4.0 MPa. Given that the significant increase in the thickness of the steel plate does not lead to a corresponding decrease in the tensile stress and adopting a thicker steel plate can significantly increase both the cost and difficulties of the structure assembled welding, the appropriate thickness of the steel plate can be selected as $15 \mathrm{~mm}$ or $20 \mathrm{~mm}$, from the perspectives of the principal tensile stress of SPRC structures.

5.2.2. Influence on the Vibration Velocity. The effects of variations in the steel plate thickness on the vibration velocity of the structural particles are shown in Figure 9. As the steel plate thickness increases, the peak value of the positive vibration velocity at point $B$ is nearly unchanged, while the peak value of the negative vibration velocity decreases significantly, and the time when the maximum particle vibration velocity appears is approximately the same. Therefore, from the particle velocity, the influence of the steel plate thickness cannot be considered during the structural design.
From Figure 9(b), the positive particle vibration velocity varies in the range of $2.8 \mathrm{~cm} / \mathrm{s}$ to $3.1 \mathrm{~cm} / \mathrm{s}$ with the increase of the steel plate thickness, while the safe particle vibration velocity is $5 \mathrm{~cm} / \mathrm{s} \sim 7 \mathrm{~cm} / \mathrm{s}$. In the engineering field, the maximum particle velocity induced by the steel plate thickness of $8 \mathrm{~mm}$ is $3.0 \mathrm{~cm} / \mathrm{s}$, which was far smaller than the safe velocity. The steel plate thickness is $10 \mathrm{~mm}, 12 \mathrm{~mm}$, and $15 \mathrm{~mm}$ for the minimum vibration velocity of $2.8 \mathrm{~cm} / \mathrm{s}$. Considering the factors of economy, stress reduction, and particle vibration velocity, the thickness of $15 \mathrm{~mm}$ is recommended.

\subsection{Influence of the Concrete Strength}

5.3.1. Influence on the Principal Tensile Stress. The nephogram and time history curves of the principal tensile stress at point $\mathrm{B}$ with different concrete strength grades are shown in Figure 10. It can be seen that, with various concrete strengths, the principal tensile stress nephogram of the composite structure is basically the same at the same, as shown in Figure 10(a). The change of the concrete strength grade does not have an obvious influence on variation trends of the principal tensile stress curves, and the time when the peak tensile stress appears on the steelconcrete interfaces is basically the same, indicating that the change of the concrete strength grade has little influence on the propagation speed of the stress waves (Figure 10(b)).

Corresponding to different concrete grades (C35, C45, $\mathrm{C} 55, \mathrm{C} 65, \mathrm{C} 75$, and $\mathrm{C} 85$ ), the maximum tensile stress value is $3.6 \mathrm{MPa}, 3.7 \mathrm{MPa}, 3.9 \mathrm{MPa}, 4.0 \mathrm{MPa}, 3.9 \mathrm{MPa}$, and 4.0 $\mathrm{MPa}$, respectively. The maximum tensile stress increases generally with the increasing concrete strength grades. However, when the concrete strength grade is greater than C55, the maximum tensile stress remains almost constant values. Note, the increase in strength grades can significantly improve the dynamic tensile/compressive ability of the concrete. Thus, a high concrete grade of C75 or C85 is recommended considering the strength of the SPRC structures. 


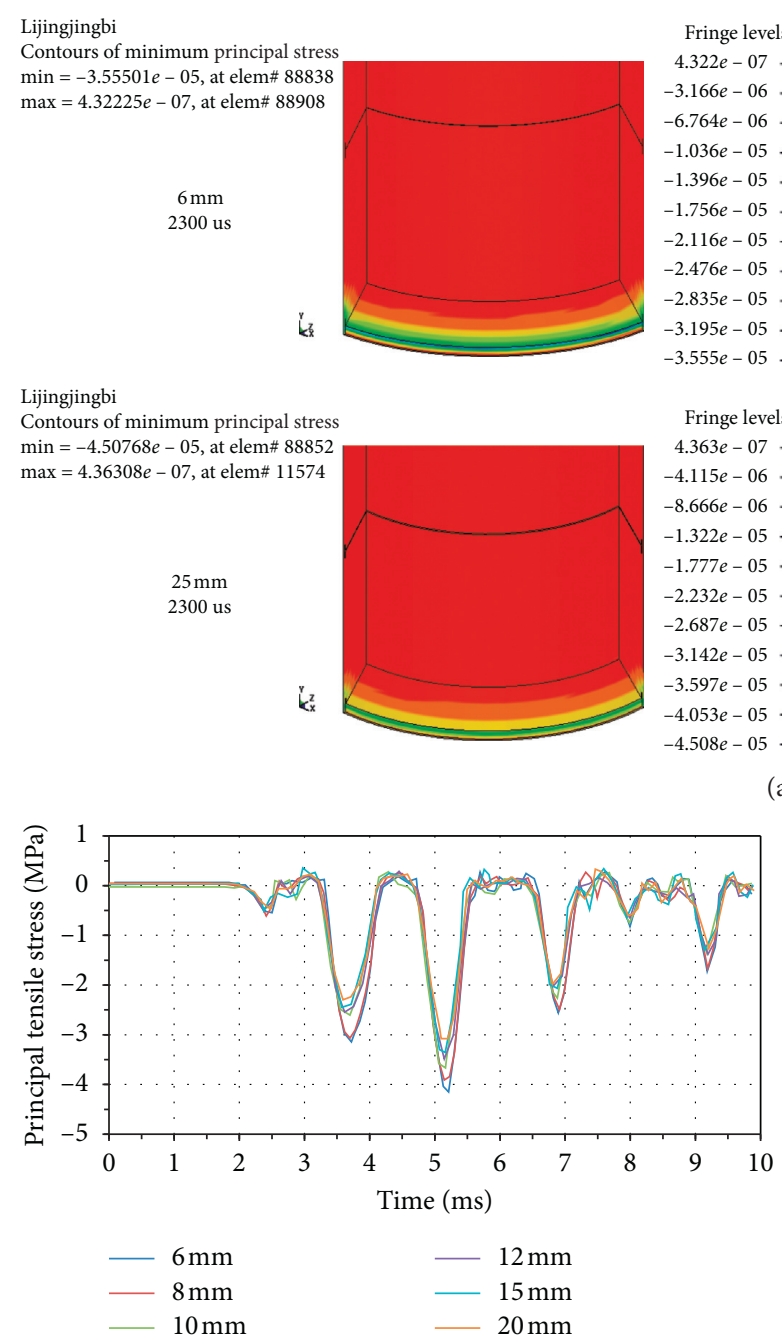

(b)

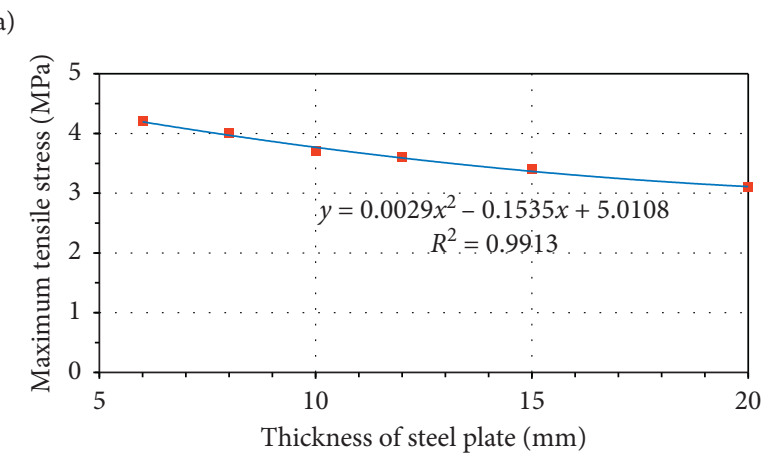

Fringe levels $4.252 e-06$ $-2.658 e-06-$ $-9.568 e-06-$ $-1.648 e-05-$ $-2.339 e-05$ $-3.030 e-05$ $-3.721 e-05$ $-4.412 e-05$ $-5.103 e-05$ $-5.794 e-05$ $-6.485 e-05$

Lijingjingbi

Contours of minimum principal stress $\mathrm{min}=-5.30667 e-05$, at elem\# 5881 $\max =3.9623 e-06$, at elem\# 20235 e -06 , at elem\# 20235

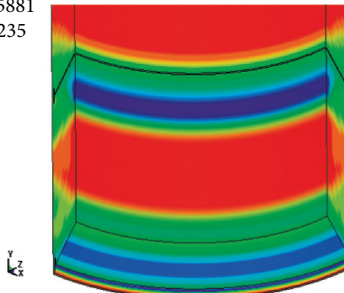
Fringe levels $3.962 e-06$ $-1.741 e-06=$ $-7.444 e-06-$ $-1.315 e-05$ $-1.885 e-05$ $-2.455 e-05$ $-3.026 e-05$ $-3.596 e-05$ $-4.166 \mathrm{e}-05$ $-4.736 e-05$ $-5.307 e-05$

(a)

FIgURE 8: Tensile stress curve corresponding to different steel plate thickness. (a) Nephogram of the principal tensile stress at the center of the steel plate. (b) Principal tensile stress curves with different steel plate thickness. (c) Maximum tension stress corresponding to different steel plate thickness.

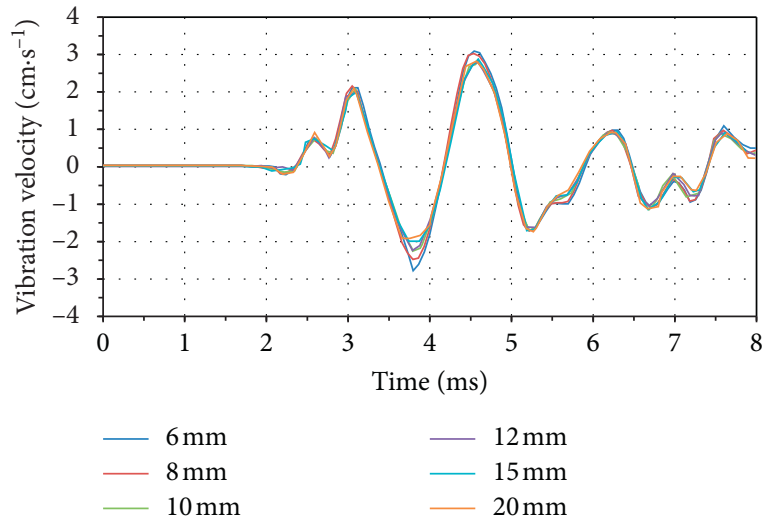

(a)

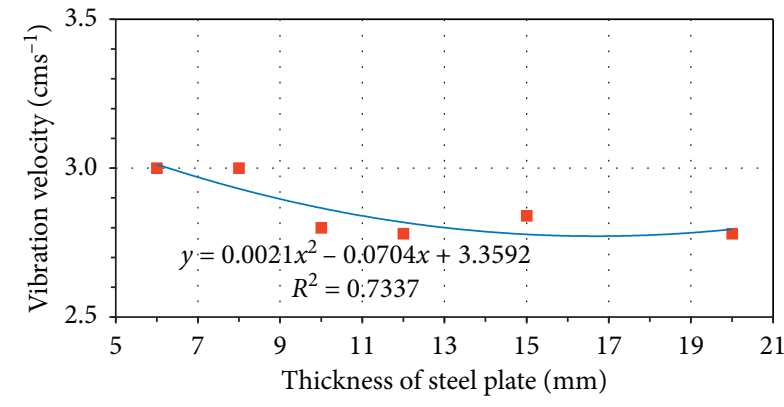

(b)

Figure 9: Vibration velocity curves corresponding to different steel plate thickness. (a) Vibration velocity curves with different steel plate thickness. (b) Vibration velocity fitting curve under different steel plate thickness. 


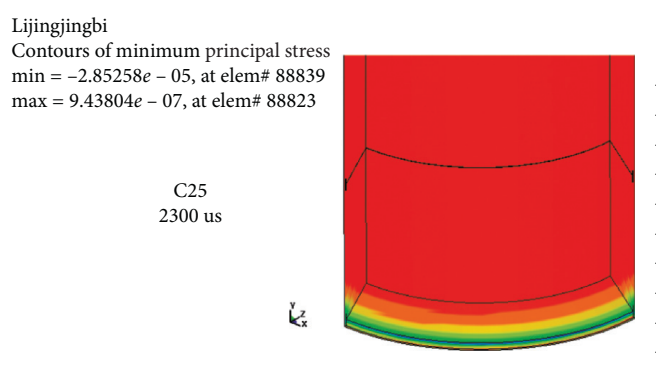

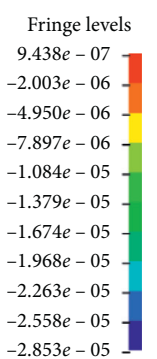

Lijingjingbi

Contours of minimum principal stres

$\min =-5.3873 e-05$, at elem 12633 $\max =3.04448 e-06$, at elem\# 86011

(n)

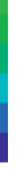

C25
5200 us

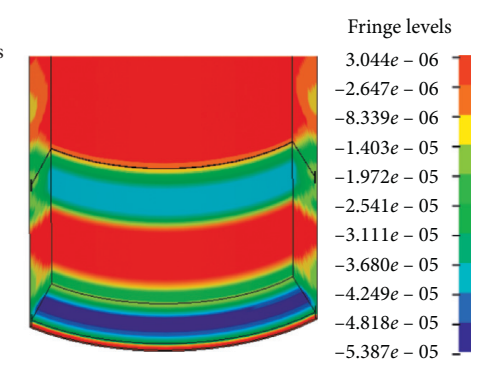

Lijingjingbi

$\begin{array}{cl}\text { Fringe levels } & \text { Contours of minimum principal stress } \\ 1.385 e-06 & \min =-5.97141 e-05 \text {, at elem\# } 12923\end{array}$

$\left.\begin{array}{rl}1.385 e-06 \\ -2.158 e-06\end{array}\right] \quad \begin{aligned} & \min =-5.97141 e-05, \text { at elem\# } 12923 \\ & \max =4.06667 e-06, \text { at elem\# } 21000\end{aligned}$

$-5.700 e-06]$

$-5.700 e-06$
$-9.243 e-06$

$-1.279 e-05-$

$-1.633 e-05-$

$-1.987 e-05$

$-2.341 e-05-$

$-2.696 e-05$

$-3.050 e-05$

$-3.404 e-05$

\section{C85 \\ 5200 us}

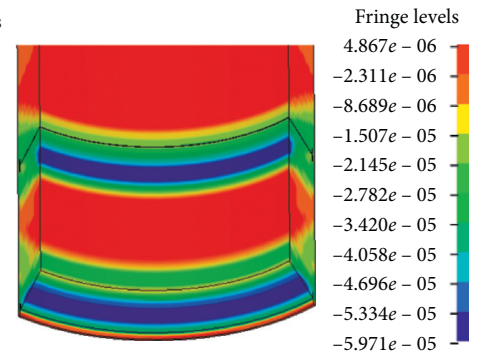

(a)

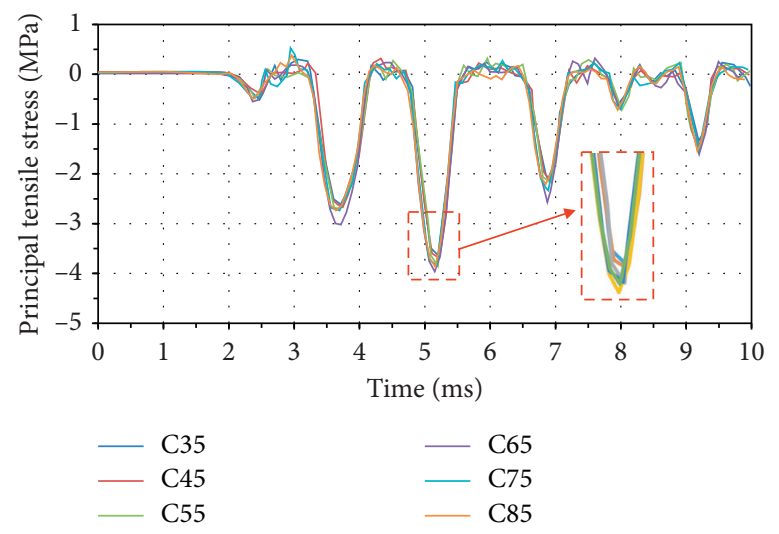

(b)

Figure 10: Principal tensile stress of the steel central position with various concrete strengths. (a) Nephogram of the principal tensile stress at the center of the steel plate. (b) Principal tensile stress curves with different concrete grades.

5.3.2. Influence on the Vibration Velocity. The influence of the concrete strength grade on the vibration velocity curves of the structural particles is shown in Figure 11. The maximum vibration velocity of particles at position $\mathrm{B}$ under six different concrete strength grades is $2.82 \mathrm{~cm} / \mathrm{s}, 2.79 \mathrm{~cm} / \mathrm{s}, 2.75 \mathrm{~cm} / \mathrm{s}$, $3.0 \mathrm{~cm} / \mathrm{s}, 2.74 \mathrm{~cm} / \mathrm{s}$, and $2.7 \mathrm{~cm} / \mathrm{s}$, respectively. With an increase in the concrete strength grade, the peak value of the particle vibration velocity first increases and then decreases. Because the change of concrete strength grades has little influence on the propagation of stress waves, the form of vibration velocity curves is similar and the extreme values appear at the same time. According to the blasting vibration criterion, the safe particle vibration velocity of the structure is $5 \sim 7 \mathrm{~cm} / \mathrm{s}$. The maximum particle velocity caused by $\mathrm{C} 65$ concrete used in actual engineering is $3.0 \mathrm{~cm} / \mathrm{s}$, and the minimum vibration velocity is $2.7 \mathrm{~cm} / \mathrm{s}$ for the concrete strength grade C55, C75, and C85. Considering the factors such as economy, reduction of stress value, and particle velocity, the strength grade of concrete is suggested to be C85.

\subsection{Influence of the Intersection Joint Angle}

5.4.1. Influence on the Principal Tensile Stress. The nephogram and time history curves of the principal tensile stress in the SPRC structures with various joint angles are shown in Figure 12. For the case of different angles between steel plates, the nephogram of the principal tensile stress varies greatly at the same time. The stress response of the composite structure begins to appear at 2300 us, while the stress value of the composite structure does not reach the maximum values at 5200 us (Figure 12(a)). It is obvious that the time when the peak stress appears is different with increasing joint angles. It is different from other factors which just affect the peak value but do not affect the corresponding time. Taking the joint angle of $45^{\circ}$ as the division, when the joint angle is greater than $45^{\circ}$, the time when the principal tensile stress reaches the maximum value is the shortest, indicating that the position with the maximum stress appears before position $\mathrm{B}$. The actual calculation results present that the 


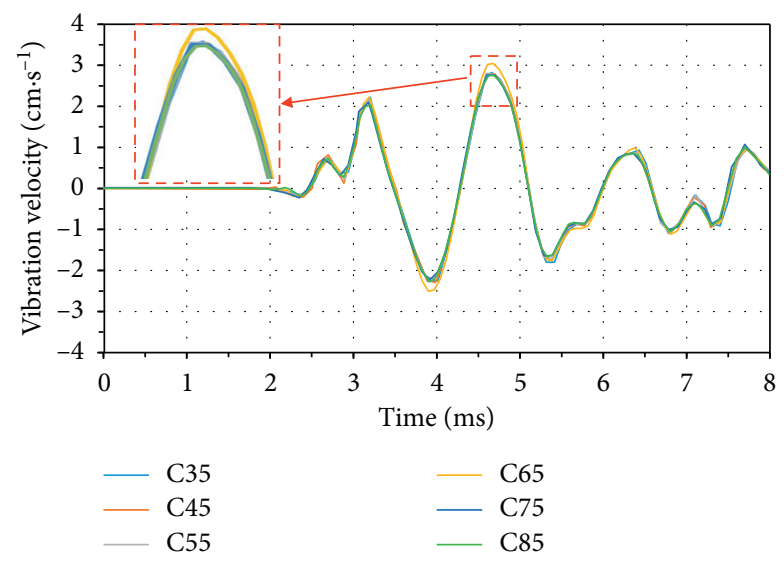

FIGURE 11: Velocity history curves under different concrete strength in the steel center.

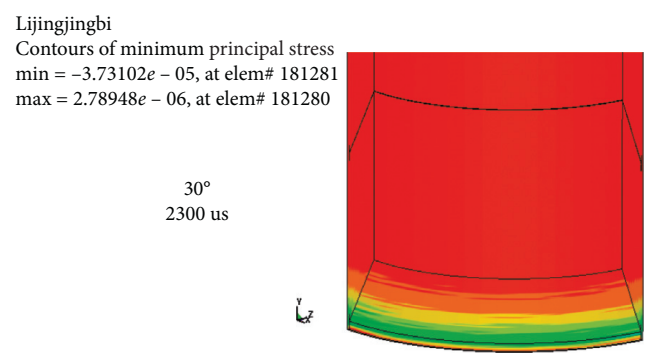

$\begin{array}{cl}\text { Fringe levels } & \text { Lijingjingbi } \\ 2789 e-06 & \text { Contours of minimum principal stress }\end{array}$

$2.789 e-06$
$-1.220 e-06$
$\min =-7.05718 e-05$, at elem $\# 11847$

$-1.220 e-06-\min =-7.05718 e-05$, at elem\# 11847
$-5.230 e-06$
$\max =6.17721 e-06$, at elem\# 181142

$-9.240 e-06$

$-9.240 e-06$
$-1.325 e-05$

$-1.726 e-05$

$-2.127 e-05-30^{\circ}$

$-2.929 e-05$

$-3.330 e-05$

$-3.731 e-05$

Lijingjingbi

Contours of minimum principal stress

$\min =-3.55671 e-05$, at elem $\# 88843$

$\max =3.28637 e-07$, at elem\# 88829

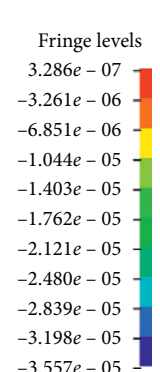

Lijingjingbi

Contours of minimum principal stres

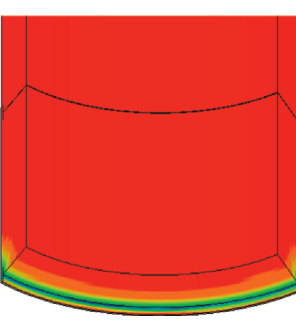

$\mathrm{min}=-0.0001026$, at elem $\# 88162$

$\max =3.75801 e-06$, at elem\# 22499

$60^{\circ}$

2300 us

$-3.557 e-05$

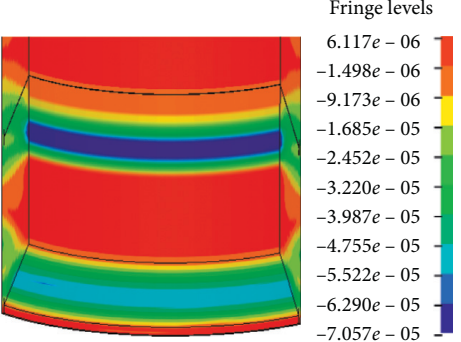

(a)
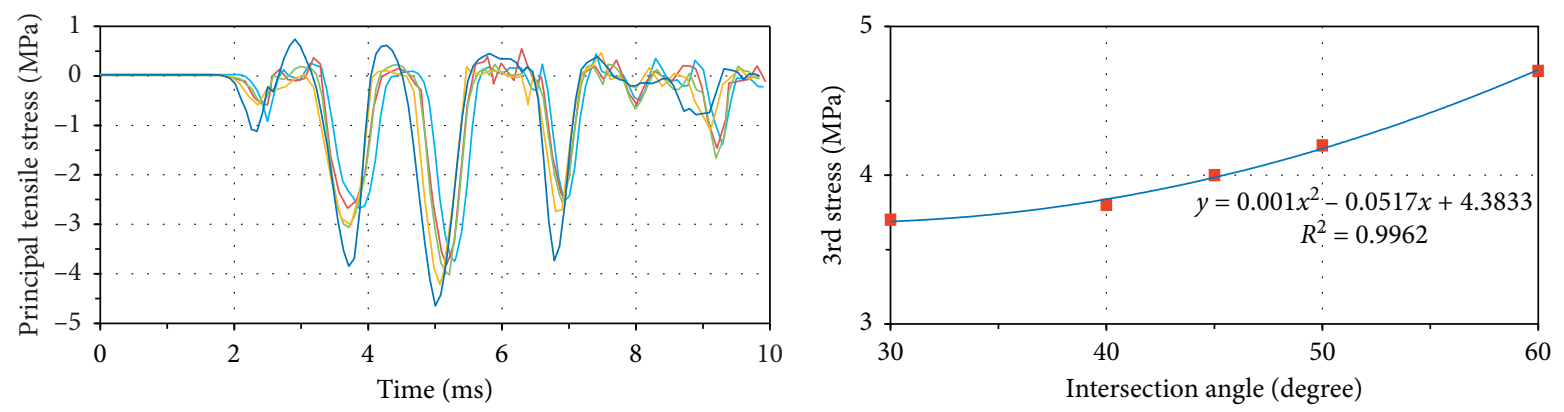

$\begin{array}{rr}30^{\circ} & -50^{\circ} \\ -\quad 45^{\circ} & 60^{\circ} \\ & 40^{\circ}\end{array}$

(b)

(c)

FIGURE 12: Relationships between the tensile stress in SPRC structures and joint angles. (a) Nephogram of the principal tensile stress at the center of the steel plate. (b) Tensile stress curves with different joint angles between two steel plates. (c) Fitting curves between the maximum tensile stress and joint angles. 


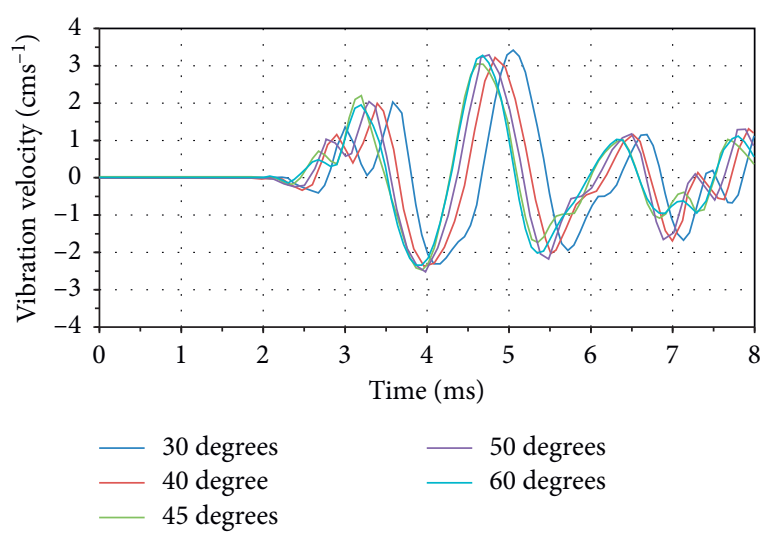

(a)

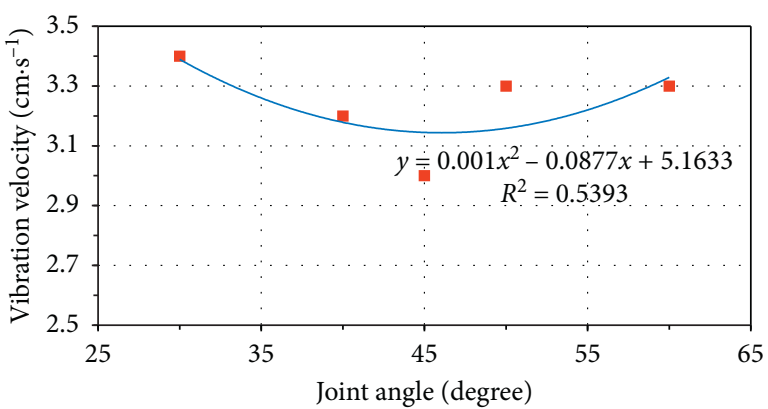

(b)

FiguRE 13: Relationships between vibration velocity and joint angles. (a) Velocity history curves with different joint angles of plates. (b) Fitting curves of vibration velocity with different joint angles.

maximum value appears at position $\mathrm{C}$, and the opposite law is true when the joint angle is less than $45^{\circ}$. The maximum tensile stress is $3.7 \mathrm{MPa}, 3.8 \mathrm{MPa}, 4.0 \mathrm{MPa}, 4.2 \mathrm{MPa}$, and 4.7 $\mathrm{MPa}$, respectively, corresponding to the five groups of joint angles. The maximum tensile stress increases with the increasing joint angle between the vertical and inclined steel plates. Therefore, the change of joint angles has a great impact on the stress responses of the SPRC structures. It is suggested that the joint angle should be reduced in the structural design to protect the SPRC structures from damage (Figure 12(b)).

From Figure 12(b), the increase in joint angles results in the increase of the maximum tensile stress in the SPRC structures, and the growth rate gradually accelerates. In the engineering field, the principal tensile stress is $4.0 \mathrm{MPa}$ when the angle equals $45^{\circ}$. Considering that the reduction of the joint angle can reduce the value of the principal tensile stress, the joint angle should be a smaller value. However, when the joint angle is reduced significantly, the tensile stress value does not significantly decrease. Moreover, too small joint angles will greatly increase the steel consumption, which will not only significantly increase the cost but also cause difficulties in the structure assembly. Therefore, considering the stress state of the structure, the appropriate joint angle is recommended to be $40^{\circ}$.

5.4.2. Influence on the Vibration Velocity. From the above studies, an obvious correspondence between the particle vibration velocity and principal stress value can be obtained; that is, the greater the principal tensile stress, the greater the negative vibration velocity of particles. Therefore, in this section, the positive vibration velocity of the particle at point $\mathrm{B}$ is mainly taken as a reference and compared with the safe vibration velocity.

The influence of the changes in the joint angle on the particle vibration velocity of the SPRC structures is shown in Figure 13. No matter how the joint angle varies, the peak value of the positive vibration velocity of the upper particle on the SPRC structures will increases, while the change range is small. When the joint angle is $60^{\circ}$ and $45^{\circ}$, the time when the particle vibration velocity reaches the maximum values is basically the same, but when the angle is $30^{\circ}$, the time to reach the maximum is later, which indicates that the maximum compressive stress is located between position $\mathrm{A}$ and position $\mathrm{B}$. Therefore, from the perspective of the particle velocity, the influence of the angle between steel plates should be considered during the structural design.

From Figure 13(b), the maximum particle vibration velocity caused by the joint angle of $45^{\circ}$ used in actual engineering is $3.0 \mathrm{~cm} / \mathrm{s}$, which is the minimum value of the particle vibration velocity. The maximum particle vibration velocity caused by the steel plate angle of $40^{\circ}$ is $3.2 \mathrm{~cm} / \mathrm{s}$, which is also within the range of the safe vibration velocity. Therefore, considering economic factors, and influences of joint angles on both stress and particle velocity, it is suggested that the joint angle should be $40^{\circ}$.

\section{Conclusions}

In this study, numerical simulations were applied to investigate the influences of the explosive payload, thickness of steel plate, concrete strength grade, and the joint angle between the inclined and vertical plates on the SPRC structures. The maximum tensile stress and vibration velocity were selected as the failure criteria. From those above studies, some conclusions can be drawn as follows:

(1) The stress analysis was carried out on the same position of the upper and lower steel joint plate structures, the maximum stress was determined at the center section of the inclined steel plates of the lower steel plate structures (position B), and this point was taken as the study object of different influence factors.

(2) The change of explosive payloads has little effect on the shape of the stress waves, but the maximum principal tensile stress and particle vibration velocity could be varied significantly. It is found that both the tensile stress and particle vibration velocity increase with the increasing explosive payload. It is suggested that the explosive payload should be less than $250 \mathrm{~kg}$. 
(3) The change of the thickness of steel plates has little effect on the shape of the stress waves. With an increase in the thickness of steel plates, the tensile stress is significantly reduced, but the particle vibration velocity is almost unchanged. It is suggested that the thickness of the steel plate should be $15 \mathrm{~mm}$.

(4) The change of concrete strength grades has little effect on the form of stress waves. With the increase in the concrete strength grades, the tensile stress and particle velocity increase and decrease, respectively. It is suggested that the strength grade of the concrete should be C85.

(5) Different from the above three factors, the change of joint angles has a great influence on the shape of stress waves and changes the propagation path of the stress waves. It is found that the principal tensile stress increases significantly with the increase of the joint angle, but the particle vibration velocity always increases with no matter decreasing or increasing joint angles. The joint angle is recommended to be $40^{\circ}$.

\section{Data Availability}

All data during this study are available from the corresponding author upon request.

\section{Conflicts of Interest}

The authors declare that they have no known conflicts of interest or personal relationships that could have appeared to influence the work reported in this paper.

\section{Acknowledgments}

The financial support from the National Natural Science Foundation of China (51874292 and 51934007); National Key Basic Research and Development Program of China (no. 2016YFC0801403), and Key Basic Research and Development Program of Jiangsu Province (no. BE2015040) is gratefully acknowledged.

\section{References}

[1] H. Dong, Y. Zhao, W. Cao, X. Chen, and J. Zhang, "Interfacial bond-slip behaviour between reinforced high-strength concrete and built-in steel plate with studs," Engineering Structures, vol. 226, no. 3, p. 111317, 2021.

[2] Q. Yin, R. Liu, H. Jing, H. Su, L. Yu, and L. He, "Experimental study of nonlinear flow behaviors through fractured rock samples after high-temperature exposure," Rock Mechanics and Rock Engineering, vol. 52, no. 9, pp. 2963-2983, 2019.

[3] T. Krauthammer, "Shallow-buried RC box-type structures," Journal of Structural Engineering, vol. 110, no. 3, pp. 637-651, 1984.

[4] T. Krauthammer, N. Bazeos, and T. J. Holmquist, "Modified SDOF analysis of RC box-type structures," Journal of Structural Engineering, vol. 112, no. 4, pp. 726-744, 1986.

[5] T. Krauthammer, A. Assadi-Lamouki, and H. M. Shanaa, "Analysis of impulsively loaded reinforced concrete structural
elements-I. theory," Computers \& Structures, vol. 48, no. 5, pp. 851-860, 1993.

[6] C.-J. Huang, X.-A. Wu, S.-J. Chen, and X.-B. Song, "Behaviors of steel-plate and concrete in steel-concrete-steel panels subjected to biaxial tension-compression," Structures, vol. 30, no. 5, pp. 217-228, 2021.

[7] K. B. Morrill, L. J. Malvar, J. E. Crawford, and J. M. Ferritto, "Blast resistant design and retrofit of reinforced concrete columns and walls," in Proceedings of the 2004 Structures Congress-Building on the Past: Securing the Future, Nashvile, TN, USA, 2004.

[8] J. W. Zhang, F. Z. Li, and S. J. Liu, "Influence of different fibers on cracking resistance of shaft wall mass concrete," Key Engineering Materials, vol. 852, pp. 150-159, 2020.

[9] P. T. Nash, C. V. G. Vallabhan, and T. C. Knight, "Spall damage to concrete walls from close-in cased and uncased explosions in air," ACI Structural Journal, vol. 92, no. 6, pp. 680-688, 1995.

[10] S. T. Dennis, J. T. Baylot, and S. C. Woodson, "Response of 1/ 4-scale concrete masonry unit (CMU) walls to blast," Journal of Engineering Mechanics, vol. 128, no. 2, pp. 134-142, 2002.

[11] J. T. Baylot, B. Bullock, T. R. Slawson, and S. C. Woodson, "Blast response of lightly attached concrete masonry unit walls," Journal of Structural Engineering, vol. 131, no. 8, pp. 1186-1193, 2005.

[12] C. D. Eamon, J. T. Baylot, J. L. O’Daniel, and L. James, "Modeling concrete masonry walls subjected to explosive loads," Journal of Engineering Mechanics, vol. 130, no. 9, pp. 1098-1106, 2004.

[13] M. Labibzadeh and R. Hamidi, "A design formula for lateral load resistance of concrete filled double-steel-plate walls with small height-to-length ratio," KSCE Journal of Civil Engineering, vol. 23, no. 4, pp. 3493-3508, 2019.

[14] A. C. Jacinto, R. D. Ambrosini, and R. F. Danesi, "Experimental and computational analysis of plates under air blast loading," International Journal of Impact Engineering, vol. 25, no. 10, pp. 927-947, 2001.

[15] M. Z. Zineddin, "Behavior of structural concrete slabs under localized impact," Doctoral dissertation, The Pennsylvania State University, University Park, PA, USA, 2002.

[16] S. Guo and D. V. Griffiths, "Failure mechanisms in two-layer undrained slopes," Canadian Geotechnical Journal, vol. 57, no. 5, pp. 1617-1621, 2020.

[17] J. Liu, Q. Fang, Z. Gong, and J. Fan, "Analysis of dynamic responses and failure modes of $\mathrm{R} / \mathrm{C}$ beams under blast loading," Explosion And Shock Waves, vol. 1, pp. 25-30, 2003.

[18] J. Liu, Q. Fang, Y. Zhang, and X. Zhao, "Analysis of local effects on steel-backed concrete composite structures under blast loading," Acta Armamentarii, vol. 6, pp. 773-776, 2004.

[19] X. Li, Y. Zheng, and G. Xu, "Local response analysis of layered structure for rock-concrete-steel panel subject to blast loading," Journal of Logistical Engineering University, vol. 4, pp. 21-24, 2007.

[20] G. Lu and R. Lin, "Calculating method for deformation of structures of reinforced concrete-steel plate against explosion action," Journal of Tongji University, vol. 5, pp. 510-512, 2000.

[21] S. Yan, B. X. Qi, H. Yan, and L. Yang, "Numerical simulation on failure modes of light steel columns under high temperature and explosion," Applied Mechanics and Materials, vol. 204-208, pp. 3351-3356, 2012.

[22] A. A. Sharba, "The efficiency of steel slag and recycled concrete aggregate on the strength properties of concrete," KSCE Journal of Civil Engineering, vol. 23, no. 5, pp. 4846-4851, 2019. 
[23] M. Zhang, "Study on the anti-blasting numerical simulation of urban shallow tunnel lining structure," Doctoral dissertation, Xi'an University of Science and Technology, Xi'an, China, 2009.

[24] K. Zhao, "The attenuation and dispersion effects on explosive wave of layered protective engineering," Doctoral dissertation, University of Science and Technology of China, Hefei, China, 2007.

[25] Z. W. Xie, X. Y. Wu, and Q. Wan, "Relation between actual mass and simulation mass of far-field underwater explosion," Applied Mechanics \& Materials, vol. 127, pp. 350-354, 2012.

[26] J. Zhou, P. Li, and N. Guo, "Seismic performance assessment of a precast concrete-encased CFST composite wall with twin steel tube connections," Engineering Structures, vol. 207, p. 110240, 2020.

[27] J. F. Hajjar, "Composite steel and concrete structural systems for seismic engineering," Journal of Constructional Steel Research, vol. 58, no. 5-8, pp. 703-723, 2002.

[28] X. Zhang, X. Yang, Z. Chen, and G. Deng, "Explosion spalling of reinforced concrete slabs with contact detonations," Journal of Tsinghua University (Science and Technology), vol. 6, pp. 765-768, 2006.

[29] S. K. Hashemi and M. A. Bradford, "Numerical simulation of free-air explosion using LS-DYNA," Applied Mechanics and Materials, vol. 553, pp. 780-785, 2014.

[30] P. Shao, Z. Dong, and Y. Zhang, "Comment on the research of rock blast models," Rock and Soil Mechanics, vol. 3, pp. 91-96, 1999.

[31] J. Zhang, "Study on the attenuation law of explosion stress wave in rock of cylinder charge," Doctoral dissertation, North University of China, Taiyuan, China, 2005.

[32] J. R. Klepaczko and A. Brara, "An experimental method for dynamic tensile testing of concrete by spalling," International Journal of Impact Engineering, vol. 25, no. 4, pp. 387-409, 2001.

[33] Z. Wang, Y. Ni, J. Cao, and W. Zhang, "Recent advance of dynamic mechanical behavior of concrete under impact loading," Explosion and Shock Wave, vol. 6, pp. 519-527, 2005. 